Dikirim: 6 April 2016 Diterbitkan:1 September 2016

\title{
Tabu, hambatan budaya pendidikan seksualitas dini pada anak di kota Dumai
}

\author{
Taboo, the culture's barrier of early sexuality education for \\ children in the city of Dumai
}

Ratna Zakiyah ${ }^{1}$, Yayi Suryo Prabandari ${ }^{2}$, Atik Triratnawati ${ }^{3}$

\begin{abstract}
Purpose: This study aimed to examine the perceptions of parents against the early sex education for children, and to provide information about the best intervention measures through sex education. Methods: This research was a descriptive exploratory study with a qualitative approach. Selection of research subjects was done by purposive sampling. Data were collected by focus group discussions (FGD) and in-depth interviews. Data analysis used discourse content analysis. Results: Results showed that the knowledge of parents in cases of children sexual abuse (CSA) was still low to minimal. The main barrier factors that prevent parents from providing sexuality education in early childhood were: felt to be an inconvenience, the perception of the child's unpreparedness, and nescience of how to deliver sexuality education to children. The availability of adequate information about sexuality, good communication and the role of fathers in sexuality education will facilitate the parents in providing sexuality education in early childhood. Conclusions: Parents need to receive more education and socialization of CSA cases that occurred in the city of Dumai. Health promoters and educators should be able to take advantage of the community forums that involve parents, such as Posyandu or school committee meetings, to promote early appropriate sexuality education for children.
\end{abstract}

Keywords: sex education; parents; Health Belief Model; child; sexual abuse

\footnotetext{
${ }^{1}$ Puskesmas Purnama Kota Dumai (Email: ratnazakiyah@gmail.com)

${ }^{2}$ Departemen Perilaku Kesehatan, Lingkungan, dan Kedokteran Sosial, Fakultas Kedokteran, Universitas Gadjah Mada

${ }^{3}$ Departemen Antropologi, Fakultas Ilmu Budaya, Universitas Gadjah Mada
} 


\section{PENDAHULUAN}

Pertengahan tahun 2014, Indonesia dikejutkan dengan berita kasus pelecehan seksual yang terjadi di sebuah sekolah internasional di Jakarta yang korban dari pelecehan seksual tersebut adalah seorang anak kelas 2 Sekolah Dasar (SD). Dari tahun ke tahun, terjadi peningkatan jumlah kasus Kekerasan Seksual pada Anak (KSA) di berbagai wilayah di Indonesia $(1,2)$.

Kekerasan Seksual pada Anak (KSA) adalah tindakan kekerasan yang dialami oleh anak yang diarahkan pada alat reproduksinya, sehingga tumbuh kembang anak secara fisik, psikis maupun sosial terganggu (1). Komnas Perlindungan Anak merilis bahwa tahun 2009 terdapat pengaduan sebanyak 1.998 kasus kekerasan pada anak. Sebanyak 62,7\% dari jumlah kasus tersebut adalah kasus kekerasan seksual dalam bentuk sodomi, perkosaan, incest dan pencabulan (1). Di Dumai, berdasarkan data Badan Keluarga Berencana (KB), Pemberdayaan Perempuan (PP) dan Perlindungan Anak (PA), pada tahun 2012 hingga tahun 2014 terjadi peningkatan jumlah kasus KSA. Hal yang lebih mengkhawatirkan, rentang usia korban adalah di bawah 10 tahun (3).

Peningkatan kasus kekerasan seksual yang terjadi pada anak menuntut perhatian yang lebih baik dari pemerintah, sekolah maupun orang tua. Anak seharusnya memiliki bekal yang cukup untuk melindungi dirinya. Salah satunya dengan memiliki bekal pendidikan seks yang memadai. Pendidikan seksualitas adalah sebuah pendekatan yang dilakukan untuk mengajarkan seks yang dilakukan dengan menyesuaikan umur sasaran serta budaya setempat melalui penyediaan informasi yang akurat secara keilmuan, realistis, dan tidak menghakimi $(4,5)$. Di era teknologi canggih saat ini, arus informasi tidak terbendung. Informasi tentang seksualitas akan mudah ditemukan di setiap tempat, sehingga peran orangtua diperlukan untuk memastikan bahwa informasi seksualitas yang diperoleh anak adalah informasi yang benar.

Orang tua adalah agen sosialisasi pertama yang memiliki kekuatan besar bagi seorang anak. Orang tua memiliki posisi yang sangat kuat dalam mempertajam sikap dan perilaku serta menolong anak agar hidup sehat (6,7). Rumah adalah tempat terbaik untuk pendidikan seks dan orangtua seharusnya menjadi sumber informasi seksualitas pertama bagi anak $(7,8)$.

Namun, topik seksualitas merupakan topik yang tabu untuk dibicarakan dalam keluarga Indonesia (9). Padahal mengawali pemberian pendidikan seksualitas pada anak, akan menolong untuk memahami tubuhnya $(8,10)$. Mengawali pembicaraan tentang seks sejak dini dan berkelanjutan adalah strategi terbaik untuk memberikan pendidikan seksualitas. Persepsi orangtua terhadap pendidikan seks akan sangat memengaruhi keinginannya dalam memberikan pendidikan seks kepada anak sejak dini. Persepsi seorang remaja terhadap pendidikan seksualitas yang ia terima dari orang tua akan menjadi lebih baik bila orang tua sering melakukan diskusi interaktif tentang seksualitas (11).

Berkaitan dengan persepsi, dalam penelitian ini, health belief model digunakan untuk menjelaskan pengaruh persepsi seseorang terhadap suatu penyakit dengan keinginannya untuk mencegah penyakit tersebut (12). Merasa terancam dengan sebuah kondisi tertentu merupakan dasar terjadinya perubahan perilaku yang memiliki relevansi yang sangat tinggi (13). Munculnya perasaan atau persepsi tersebut akan menjelaskan faktor-faktor yang melatarbelakangi perubahan perilaku seseorang termasuk faktor-faktor yang menyebabkan orangtua mau memberikan pendidikan seksualitas dini kepada anak mereka.

Berdasarkan uraian di atas, persepsi orangtua terhadap pendidikan seksual pada anak usia dini penting untuk dikaji. Pengetahuan mengenai persepsi orang tua ini akan menunjang langkah-langkah intervensi yang dapat dilakukan dalam mengatasi permasalahan penyimpangan seksual melalui peran orang tua. Penelitian ini bertujuan untuk mengeksplorasi persepsi orangtua di Kota Dumai tentang pendidikan seksualitas dini pada anak. Berkaitan dengan tujuan tersebut, peneliti akan menggali persepsi orangtua tentang pendidikan seksualitas dini pada anak, persepsi orangtua tentang kasus kekerasan seksual pada anak, serta faktor-faktor yang menghambat dan mempermudah orangtua dalam memberikan pendidikan seksualitas dini pada anak.

\section{METODE}

Penelitian ini merupakan penelitian deskriptif eksploratif dengan pendekatan kualitatif. Pendekatan ini merupakan suatu metode penelitian yang diharapkan dapat menghasilkan deskripsi tentang ucapan, tulisan, atau perilaku yang dapat diamati dari semua individu, kelompok, masyarakat atau organisasi tertentu dalam suatu latar tertentu (14).

Dalam penelitain kualitatif, peneliti merupakan salah satu instrumen dalam penelitian itu sendiri. Data yang dikumpulkan merupakan data primer. Data diambil dengan menggunakan metode wawancara mendalam dan focus group discussion (FGD). FGD dilakukan untuk menggambarkan dan memahami 
persepsi, interpretasi dan kepercayaan dari populasi terpilih (15).

Penelitian ini dilakukan kepada orangtua yang memiliki anak usia 5-10 tahun. Hal ini didasari pada beberapa penelitian yang menunjukkan bahwa rentang usia tersebut adalah usia yang tepat untuk memberikan pendidikan seksualitas dini pada anak $(8,10)$. Selain itu, usia ini dipilih karena korban KSA yang terjadi di Dumai berada di rentang usia 5-10 tahun.

Peserta FGD adalah 5 orang ibu-ibu kader posyandu yang memiliki anak usia 5-10 tahun. FGD dipandu oleh peneliti dan dibantu oleh 1 orang asisten peneliti yang bertugas mengambil gambar selama proses FGD dan membantu menulis catatan lapangan. Setiap peserta FGD mendapatkan kompensasi berupa souvenir dari peneliti.

Informan wawancara mendalam berjumlah 6 orang dengan kriteria orang tua yang memiliki anak usia 5-10 tahun di lingkungan kerja terdekat peneliti. Hal ini dilakukan untuk membangun kedekatan dengan informan karena topik seksualitas adalah topik yang masih belum umum untuk dibicarakan.

Wawancara mendalam dilakukan kepada 4 orang ibu dan 2 orang ayah dengan latar belakang sosial, ekonomi, pendidikan, status pernikahan dan agama yang berbeda-beda. Selain itu, wawancara mendalam juga dilakukan kepada salah satu kepala bidang di Badan Perlindungan Anak dan Perempuan Kota Dumai, kepala sekolah dan guru Penjaskes.

Setelah melakukan FGD dan wawancara mendalam, peneliti melakukan transkrip terhadap data yang didapat. Setelah itu, dilakukan analisis awal terhadap data yang didapat untuk melihat kemungkinan informasi yang belum tergali. Data yang telah ditranskrip dianalisis secara lengkap dengan bantuan software opencode versi 3.6.

Analisis data dilakukan dengan content analysis yang terdiri dari beberapa langkah, seperti membuat kategori-kategori atas informasi yang diperoleh (open coding), memilih salah satu kategori dan menempatkannya dalam satu model teoritis (axial coding), kemudian merangkai sebuah cerita dari hubungan antar kategori ini (selective coding). Untuk menjamin keabsahan data, peneliti melakukan cek ulang hasil transkrip, memastikan tidak ada makna yang mengambang selama proses coding, triangulasi sumber data dan melakukan peer the brief(16).

Perizinan penelitian dari Kantor Kesbanglinmas Kota Dumai disetujui melalui surat rekomendasi bernomor : 134.071/ II/ 2015/ 24. Penelitian ini juga sudah mendapatkan izin dari Komisi Etik Fakultas
Kedokteran dengan nomor Ref : KE/FK/ 350/ EC. Sebelum melakukan FGD maupun wawancara mendalam, peneliti mengawalinya dengan penjelasan tujuan penelitian dan pengisian informed consent.

\section{HASIL}

Dalam penelitian ini, peneliti menggali 4 tema besar, yaitu: persepsi orang tua terhadap kasus kekerasan seksual pada anak, persepsi orangtua terhadap pendidikan seksualitas dini pada anak, faktor penghambat dan pemudah orangtua dalam memberikan pendidikan seksualitas dini pada anak. Hasil penelitian dapat dilihat lebih lengkap dari tabel di bawah ini.

Tabel.I. Hasil penelitian persepsi orang tua terhadap pendidikan seksualitas dini pada anak di Kota Dumai

\begin{tabular}{|c|c|}
\hline Tema & Hasil \\
\hline $\begin{array}{l}\text { Persepsi orang } \\
\text { tua terhadap } \\
\text { kasus } \\
\text { kekerasan } \\
\text { seksual pada } \\
\text { anak di Kota } \\
\text { Dumai }\end{array}$ & $\begin{array}{l}\text { a. Pengetahuan terhadap kasus KSA masih } \\
\text { minim karena jarang dibicarakan } \\
\text { b. Orang tua yang hanya memiliki anak } \\
\text { laki-laki, merasa kurang khawatir anak } \\
\text { menjadi korban KSA karena yang lebih } \\
\text { rentan menjadi korban KSA adalah anak } \\
\text { perempuan } \\
\text { c. Pesan seksualitas muncul melalui bebagai } \\
\text { macam media } \\
\text { d. Kemajuan teknologi seperti internet dan } \\
\text { gadget merupakan salah satu penyebab } \\
\text { terjadinya KSA }\end{array}$ \\
\hline $\begin{array}{l}\text { Persepsi } \\
\text { orangtua } \\
\text { terhadap } \\
\text { pendidikan } \\
\text { seksualitas dini } \\
\text { pada anak di } \\
\text { Kota Dumai }\end{array}$ & $\begin{array}{l}\text { a. Pendidikan seksualitas dini adalah hal yang } \\
\text { porno untuk dibicarakan } \\
\text { b. Mengajarkan pendidikan seksualitas sama } \\
\text { artinya dengan mengajarkan hubungan } \\
\text { seksual pada anak } \\
\text { c. Pengetahuan terhadap pendidikan } \\
\text { seksualitas dini pada anak masih rendah } \\
\text { d. Orangtua berkeinginan mengajarkan } \\
\text { pendidikan seksualitas agar anak tidak } \\
\text { mendapat informasi yang salah dari orang } \\
\text { luar }\end{array}$ \\
\hline
\end{tabular}

$\begin{array}{lll}\begin{array}{l}\text { Faktor-faktor } \\ \text { yang }\end{array} \quad \text { b. } & \begin{array}{l}\text { Ketidaknyamanan atau risih } \\ \text { Persepsi bahwa anak belum siap untuk } \\ \text { diajak berdiskusi tentang seksualitas } \\ \begin{array}{l}\text { menghambat } \\ \text { memberikan }\end{array}\end{array} & \begin{array}{l}\text { Ketidaktahuan tentang cara menyampaikan } \\ \text { pendidikan seksualitas pada anak }\end{array} \\ \begin{array}{l}\text { pendidikan } \\ \text { seksualitas dini } \\ \text { pada anak di }\end{array} & \\ \text { Kota Dumai } & \end{array}$

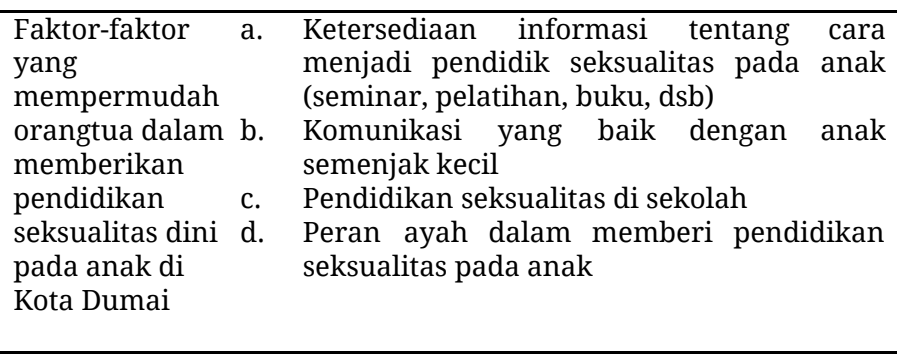

Persepsi orang tua terhadap kasus kekerasan seksual pada anak. Secara umum, informan merasa 
khawatir apabila anak informan menjadi korban kekerasan seksual. Namun, pengetahuan informan terhadap kasus kekerasan seksual yang terjadi di Kota Dumai masih sangat minim sekali. Ada perbedaan kekhawatiran antara orangtua yang memiliki anak laki-laki dan perempuan. Seperti yang diungkapkan oleh informan berikut ini:

"Kalau saya, anak saya laki-laki. Terus terang takutnya diculik. Kalau seks, kasihan yang punya anak perempuan. Besok mana tahu (punya) anak perempuan kan, khawatir juga.”

(FGD kelompok ibu)

Menurut informan, kemajuan teknologi merupakan salah satu hal yang dianggap sebagai pemicu terjadinya kasus kekerasan seksual pada anak. Selain itu, konten seksual saat ini hadir dalam berbagai macam cara seperti melalui lagu-lagu, sinetron ataupun film yang tayang saat ini.

"Tapi sekarang, sinetron-sinetron sekarang, tersipu-sipu dia. Adegan-adegan sinteron sekarang gawat-gawat. Mulai dari sinilah istilahnya.”

(RB, 39 tahun)

Persepsi orang tua terhadap pendidikan seksualitas dini pada anak. Hampir semua informan berpendapat bahwa pendidikan seksualitas itu adalah sesuatu hal yang porno dan tabu. Para informan mengungkapkan bahwa memberikan pendidikan seksualitas berarti mengajarkan anak tentang hubungan seksual, sehingga ketika memberikan pendidikan seksualitas itu artinya mengajarkan anak untuk melakukan hubungan seksual.

"Seperti apa ya? Tentang cumbu-cumbuan atau istilahnya tentang tata cara yang istilahnya suami ke istri. Mungkin mau diterangkan, tapi istilahnya tunggulah dia dewasa sedikit.”

(S, 34 tahun)

Namun, ada juga informan yang menyadari bahwa tuntutan zaman membuat mereka harus memberikan pendidikan seksualitas pada anak. Menurut informan, jika pendidikan seksualitas diajarkan oleh orang tua maka anak akan selalu menjadikan orang tuanya sebagai pusat rujukan informasi, sehingga jika anak mendapat informasi yang berbeda dari luar, maka anak akan berpegang pada informasi dari kedua orangtuanya.
"Jika kita, pertama tidak mempedulikannya misalnya, tentu lambat laun dia akan mencari di tempat yang lain. Kalau seandainya jawaban tempat lain itu menyimpang, tentu dalam pikirannya akan menyimpang. Tapi kalau kita yang menjawab dan jawaban kita tepat, sesuai dengan logikanya, sesuai dengan nalarnya sebagai anak kecil, saya rasa ke depannya nanti dia akan,"Ohh jawaban dari orangtua saya kemarin lain".

(Z, 37 tahun)

Faktor-faktor yang menghambat orang tua dalam pendidikan seksualitas dini pada anak. Faktor pertama adalah ketidaknyamanan atau risih. Hampir semua informan mengatakan bahwa ketidaknyamanan atau perasaan risih adalah kendala utama mereka dalam memberikan pendidikan seksualitas pada anak. Mereka merasa saat membicarakan pendidikan seksualitas seolah sedang membicarakan hal yang porno pada anak.

"Sebaiknya kalau sudah mulai pubertas ya, sepertinya sudah wajib diberi tahu. Tapi kakak bingung bagaimana membahasakannya. Kita orang tua, seperti porno begitu."

( $R B, 39$ tahun)

Faktor kedua adalah persepsi ketidaksiapan anak untuk berdiskusi tentang seksualitas. Kendala lain yang dihadapi orang tua dalam memberikan pendidikan seksualitas adalah persepsi bahwa anak belum siap dalam menerima pendidikan seksualitas. Menurut mereka, anak belum memiliki nalar yang cukup dalam menerima pendidikan seksualitas. Informan mengata- kan bahwa usia yang sesuai untuk menyampaikan pendidikan seksualitas pada anak adalah saat anak akan memasuki usia pubertas

"Karena mungkin menurut mbak, anak-anak perempuan, terutama yang perempuan ya, pubernya lebih cepat. Mbak terasa anak kelas 4 SD saja, 9 tahun, sepertinya rasa ingin tahunya banyak. Makanya di sanalah kita masukkan sedikit demi sedikit. Lebih cepat mengerti.

( $Y, 38$ tahun)

Faktor ketiga adalah ketidaktahuan tentang cara menyampaikan pendidikan seksualitas pada anak. Sebagian besar informan merasa bingung saat harus menjawab pertanyaan seksualitas dari anak. Informan kesulitan dalam mencari kalimat yang baik dan tepat saat menjelaskan pendidikan seksualitas pada anak. 
Saat mereka kecil pun orang tua mereka tidak mengajari mereka tentang seksualitas, sehingga mereka juga tidak tahu cara menyampaikan pada anak-anak mereka.

"Kata-kata yang sesuai, kata-kata yang bisa diterima. Kata-kata yang baik, kata-kata yang indah untuk dua. Kalau orang Melayu, kasarlah ya kalau untuk orang Melayu ini. Tapi mengerti. Tapi tidak ingin seperti itu. Istilahnya ingin bagaimana yang bagus. Yang pertama kalinya, dari pertama kata-kata yang baiklah. Itulah yang susah, menerjemahkan katakatanya itu bagaimana ya, pertama kalinya.”

(S, 34 tahun)

Faktor-faktor yang mendorong orang tua dalam memberikan pendidikan seksualitas dini pada anak. Faktor pertama adalah ketersediaan informasi tentang cara menjadi pendidik seksualitas pada anak. Semua informan belum pernah mengikuti seminar, pelatihan ataupun bentuk diseminasi informasi lain yang ber- temakan pendidikan seksualitas pada anak. Menurut mereka, adanya sumber informasi tentang cara me- nyampaikan pendidikan seksualitas pada anak akan memudahkan mereka. Seperti yang diungkapkan oleh informan berikut ini:

"Akan memudahkan. Istilahnya senang berbicara seperti ini. Mungkin kalau belum tahu, bagaimana ya, pertamanya, bahasanya bagaimana, bingung, memang iya."

\section{(S, 34 tahun)}

Faktor kedua adalah komunikasi yang baik dan terbuka dengan anak sejak kecil. Menurut informan, saat anak selalu terbuka menceritakan apapun kepada orang tuanya, maka komunikasi yang baik akan muncul, sehingga hal ini akan memudahkan untuk menanamkan nilai-nilai kepada anak termasuk pendidikan seksualitas. Hal ini diungkapkan oleh informan sebagai berikut :

"Dulu kami dengan ibu kami tidak begitu terbuka. Entah seperti apa tidak tahu. Setelah kami pikirkan, dulu ibu kami tidak terbuka. Sekarang saya anggap anak kami teman. Kadang saya ingin marah, kadang apa itu begini-begini? Anak tidak ingin membicarakannya. Kalau teman, begini Bu, diceritakan semua, sehingga saya mendapatkan informasi.”

(S, 34 tahun)
Faktor ketiga adalah pendidikan seksualitas di sekolah. Bagi beberapa informan, pelajaran seksualitas di sekolah diharapkan dapat membantu menjelaskan tentang pendidikan seksualitas. Bagi sebagian informan, guru adalah orang yang tepat dalam menyampaikan pendidikan seksualitas untuk anak. Seperti yang diungkapkan oleh informan berikut ini :

"Tapi jangan kita yang melakukannya. Entah gurunya atau siapa. Penempatannya lebih sesuai. Kalau seperti saya, porno itu, lain pula dia nanti.”

(FGD ibu)

Faktor keempat adalah peran ayah dalam memberikan pendidikan seksualitas dini pada anak. Menurut informan yang memiliki anak laki-laki, mereka berharap bahwa ayahlah yang akan mengambil peran dalam memberikan pendidikan seksualitas pada anak laki-lakinya. Hal ini karena ketika pembicaraan seksualitas laki-laki disampaikan oleh laki-laki maka pembicaraan akan lebih nyaman. Seperti diungkapkan oleh informan berikut ini :

“Oh, pernah. Seperti kemarin itu, si kakak, namanya anak bujang, kan sudah tumbuh rambut di kemaluannya, dia teriak-teriak, panik. Kan dia orangnya sedikit reaktif. Mbak ketika sholat magrib. "Kenapa kakak? Kenapa kakak?". "Bundaaa sini bunda. Astaghfirullah al'adziim bunda..". Mungkin sesuatu yang aneh untuk dia. "Kenapa kak?". "Ini apa bunda? kok tumbuh bulu di sini?". "Astagfirullah al'adzim ..Papaa..papa..". Jadi teriak juga. "Kenapa ni kok teriak-teriak magrib-magrib berdua ni?". "Anakmu tu..urusan papa". Hahaha...jadilah papanya yang berbicara. "Iya..itu emang gitu kak..itu harus dibersihkan. Kalo ga, ntar ketombean." Hahaha..."

$$
\text { ( } Y, 38 \text { tahun) }
$$

\section{BAHASAN}

Berdasarkan hasil penelitian, semua orang tua memiliki kekhawatiran anaknya menjadi korban KSA. Namun, ternyata hal tersebut tidak didukung dengan langkah pencegahan yang lebih nyata. Ini terjadi salah satunya karena pembahasan tentang kasus KSA dalam forum-forum formal masih jarang (17). Pembahasan KSA sering hanya menjadi pembicaraan sepintas lalu saja. Padahal orang tua berpotensi mengembangkan kemampuan dalam melindungi anaknya dari kekerasan seksual apabila orang tua memiliki informasi yang cukup terkait prevalensi kasus kekerasan seksual pada 
anak (KSA), keseriusan terhadap kasus tersebut dan strategi pencegahannya (12).

Pelaku KSA seringkali merupakan orang terdekat korban. Saat ini, jarang sekali kasus KSA yang melibatkan orang asing. Ancaman terbesar KSA justru berasal dari orang yang dikenal $(17,18)$. Hal ini seharusnya lebih mendorong orang tua untuk memberikan bekal perlindungan diri pada anak. Perlindungan diri yang dimaksud tidak hanya tentang olahraga bela diri, namun juga pengenalan terhadap perilaku yang melewati batas area pribadi pada tubuhnya atau potensi pelecehan seksual. Anak harus mulai diajari tentang tubuhnya dan batas area pribadi yang boleh disentuh atau tidak dan orang-orang yang boleh menyentuhnya $(17,19,20)$.

Penelitian ini juga menunjukkan bahwa kemajuan teknologi harus diwaspadai sebagai salah satu pemicu terjadinya kasus KSA. Hampir semua hal yang ada saat ini menjurus ke arah pornografi $(21,22)$. Orangtua seharusnya memberikan pendampingan penuh terhadap penggunaan teknologi oleh anak baik itu dari tayangan televisi, penggunaan internet dan gadget.

Salah satu hal yang dapat melindungi anak dari KSA adalah dengan memberikan pendidikan seksualitas pada anak. Namun, terminologi pendidikan seksualitas sering kali diartikan sebagai suatu hal yang porno oleh sebagian masyarakat di Indonesia. Seksualitas menjadi sebuah pembicaraan tabu dalam keluarga. Hasil temuan peneliti pun sejalan dengan hasil penelitian sebelumnya (23). Prinsip pendidikan seks sesungguhnya mengacu pada healthy sexual life, bahwa seks adalah sesuatu yang alami dan sehat. Pendidikan seks tidak bersifat porno dan tidak mendorong remaja untuk berhubungan seks tetapi mendorong remaja untuk dapat bertanggung jawab atas perilaku seksnya(24).

Orang tua sebenarnya menyadari bahwa mereka memiliki peran agar anak tidak terpapar dengan informasi seksualitas yang salah dari luar. Saat orang tua mau membicarakan seksualitas pada anak, hal ini akan membuat orang tua memiliki otoritas penuh pada anak sehingga mereka akan selalu menjadi rujukan bagi anak $(22,25)$. Sama halnya dengan mengajarkan keterampilan lainnya, pendidikan seksualitas pun juga dapat diajarkan kepada anak sesuai dengan usia, nalar dan kesiapan mereka dalam menerima informasi tersebut $(20,27)$.

Pengenalan terhadap anatomi tubuh anak merupakan salah satu hal yang bisa diajarkan pada anak semenjak dini. Akan tetapi, hal yang sering terjadi adalah hampir semua informan menggunakan terminologi yang tidak sebenarnya saat menyebutkan alat kelamin anak mereka. Padahal, memperkenalkan anak dengan istilah alat kelamin yang benar adalah hal yang penting untuk dilakukan agar anak tidak mengalami kebingungan terhadap tubuhnya sendiri.

Ketidaknyamanan adalah salah satu hal yang menghambat semua informan untuk berbicara seksualitas pada anak. Mereka merasa risih berbicara seksualitas pada anak karena seakan mengajarkan anak untuk berhubungan seksual (22). Orangtua menganggap topik seksualitas adalah topik yang cukup berat untuk anak dan anak tidak siap untuk menerimanya. Hal ini dapat diatasi apabila orangtua memahami tahapan perkembangan anak, sehingga orang tua dapat mengukur materi seksualitas yang tepat mereka sampaikan kepada anak.

Saat orang tua mengalami kebingungan untuk menyampaikan pendidikan seksualitas pada anak, orang tua dapat menggunakan alat bantu media lain untuk memulai diskusi seksualitas dengan anak, seperti dengan memanfaatkan buku, majalah, tayangan televisi, lagu ataupun hal lain yang berhubungan dengan seksualitas (22). Semakin sering orang tua membicarakan topik seksualitas, perlahan-lahan akan mengurangi rasa ketidak- nyamanan berbicara seksualitas pada anak. Namun tetap, usia dan daya nalar anak selalu menjadi rujukan utama saat memulai diskusi seksualitas.

Saat ketidaknyamanan menghilang, maka akan muncul keterbukaan antara anak dan orang tua untuk berdiskusi tentang seksualitas. Seringkali, orang tua bereaksi terlalu berlebihan saat anak bertanya tentang seksualitas. Reaksi orang tua akan sangat menentukan kepercayaan dan kenyamanan anak untuk berbicara seksualitas dengan mereka. Bila tidak nyaman, maka mereka akan mencari jawaban dari dunia luar.

Menjalin komunikasi yang terbuka sejak dini dengan anak akan menciptakan jalinan hubungan yang lebih mendalam. Saat hubungan terjalin nyaman, anak akan terbiasa untuk mendiskusikan berbagai hal dengan orang tua. Bagi orang tua, hal yang perlu diperhatikan bukan hanya tentang materi yang akan disampaikan kepada anak, akan tetapi pertimbangan hubungan yang telah terjalin antara orang tua dan anak juga memiliki peran penting. Jalinan komunikasi yang baik, kepercayaan yang tumbuh dan penghargaan antara orang tua dan anak adalah hal yang cukup menunjang agar pesan dapat tersampaikan dengan baik (17).

Hal lain yang dapat mendorong orang tua untuk menyampaikan pendidikan seksualitas dini pada anak adalah ketersediaan informasi. Orang tua membutuhkan ilmu dan informasi tentang cara menjadi 
pendidik seksualitas anak. Hal ini masih sangat langka terdapat di Kota Dumai dan di daerah lain. Kegiatan seminar, pelatihan atau diseminasi informasi lain yang bertema seksualitas masih sangat jarang diadakan oleh pemerintah. Kegiatan ini masih banyak diinisiasi oleh LSM-LSM atau organisasi kemasyarakatan lain yang peduli dengan pendidikan seksualitas anak. Padahal di negara lain, program untuk menjadi pendidik seksualitas anak ternyata terbukti efektif untuk menumbuhkan kepercayaan diri orang tua menjadi pendidik seksualitas anak (27).

Dalam pendidikan seksualitas, seharusnya peran ayah juga tidak bisa diabaikan. Selama ini, praktik pengasuhan anak masih bertumpu pada ibu. Padahal, peran ayah dan ibu dalam pengasuhan akan selalu saling melengkapi. Salah seorang informan berpendapat bahwa seksualitas anak laki-laki seharusnya dibahas oleh sesama laki-laki. Hal ini sesuai dengan hasil penelitian lain (25). Namun, keterlibatan ayah seharusnya tidak hanya pada pendidikan seksualitas anak laki-laki, tetapi juga pada anak perempuan (28). Bagi anak perempuan, ayah adalah laki-laki pertama dalam kehidupannya (29). Sifat pengasuhan ayah yang lebih tegas dan berwibawa, dapat dimanfaatkan untuk menanamkan nilai-nilai tentang pentingnya menjaga kesehatan reproduksi saat mereka sudah mengalami pubertas.

\section{SIMPULAN}

Pendidikan seksualitas masih merupakan pembicaraan yang porno atau cabul dalam keluarga. Orang tua masih enggan membicarakan seksualitas pada anak karena merasa risih dan tidak tahu cara menyampaikannya. Strategi intervensi seharusnya dilakukan untuk memperkaya orang tua dengan informasi pendidikan seksualitas yang tepat dan sesuai dengan usia dan tahap perkembangan anak. Melalui hal tersebut, diharapkan orang tua memiliki kepercayaan diri untuk menjadi pendidik seksualitas bagi anaknya. Tenaga promosi kesehatan hendaknya dapat memanfaatkan forum-forum yang banyak melibatkan orangtua seperti pertemuan komite sekolah, posyandu, ataupun dasawisma untuk mensosialisasikan pendidikan seksualitas dini yang tepat bagi anak. Selain itu, tenaga promosi kesehatan perlu membuat media promosi kesehatan bertemakan pendidikan seksualitas seperti leaflet, poster atau baliho.

\section{Abstrak}

Tujuan: Penelitian ini bertujuan untuk menggali persepsi orangtua terhadap pendidikan seks dini pada anak akan memberikan informasi tentang langkah intervensi yang terbaik melalui pendidikan seks. Metode: Penelitian ini adalah penelitian deskriptif eksploratif dengan pendekatan kualitatif. Pemilihan subjek penelitian dilakukan dengan purposive sampling. Pengambilan data dilakukan dengan focus group discussion (FGD) dan wawancara mendalam. Analisis yang digunakan adalah content analysis. Hasil: Pengetahuan orang tua terhadap kasus Kekerasan Seksual pada Anak (KSA) masih minim. Faktor penghambat utama yang menghalangi orang tua memberikan pendidikan seksualitas dini pada anak adalah ketidaknyamanan, persepsi ketidaksiapan anak dan ketidaktahuan cara menyampaikan pendidikan seksualitas pada anak. Ketersediaan informasi yang cukup tentang seksualitas, komunikasi yang baik dan adanya peran ayah dalam pendidikan seksualitas akan memudahkan orang tua dalam memberikan pendidikan seksualitas dini pada anak. Simpulan: Orang tua masih menganggap pendidikan seksualitas sebagai topik pembicaraan yang tabu dalam keluarga. Tenaga promosi kesehatan hendaknya lebih dapat memanfaatkan forum-forum yang melibatkan orangtua, seperti posyandu atau pertemuan komite sekolah, untuk menyosialisasikan pendidikan sek- sualitas dini yang tepat bagi anak.

Kata kunci: pendidikan seks; orang tua; Health Belief Model; anak; kekerasan seksual

\section{PUSTAKA}

1. Kementrian PP\&PA. Peraturan Menteri Negara Pemberdayaan Perempuan dan Perlindungan Anak RI No 08 Tahun 2012. Jakarta: Kementrian Negara Pemberdayaan Perempuan dan Perlindungan Anak RI. 2012.

2. Yusuf, AH, Yugiana, E, Nuryetty, MT, Handiyatmo, D, Wajdi, N, Wirananggapattie, TI, Saleh, AM. Profil Anak Indonesia 2012, Jakarta: Kerjasama Kementrian Pemberdayaan Perempuan \& PA dengan BPS. 2012.

3. Badan PP, PA \& KB. Laporan Tahunan Badan Pemberdayaan Perempuan, Perlindungan Anak dan Keluarga Berencana, Kota Dumai: Badan KB, Pemberdayaan Perempuan \& Perlindungan Anak. 2013.

4. UNESCO. International Technical Guidance on Sexuality Education: An Evidence-Informed Approach for Schools, Teachers and Health Educators, Perancis: UNESCO.2009.

5. Nirna S. Bimbingan Seks Bagi remaja. Bandung: Remaja Rosda karya. 2001.

6. Crosby RA, Miller KS. Family influences on adolescent females' sexual health. In Handbook 
of women's sexual and reproductive health 2002 (pp. 113-127). Springer, Boston, MA.

7. Elizar. Persepsi Remaja tentang Gaya Pengasuhan Orang Tua dengan Perilaku Seksual Remaja SMU di Kota Lhoksumawe. Thesis, Universitas Gadjah Mada. 2010.

8. Opara PI, Eke GK, Akani NA. Mothers perception of sexuality education for children. Nigerian journal of medicine. 2010;19(2).

9. Situmorang, A, Traggiai, C, Stanhope, R, Hickey, M, Balen, A, Van Der Mei, J, Heijstra, T, Boersma, E, Christie, D, Viner, R. Adolescent reproductive health in Indonesia. Best Practice and Research Clinical Obstetrics and Gynaecology. 2013. 17(1): 41-56.

10. Fentahun N, Assefa T, Alemseged F, Ambaw F. Parents' perception, students' and teachers' attitude towards school sex education. Ethiopian journal of health sciences. 2012;22(2).

11. Davies, M. \& Macdowall, W. (2006) Health Promotion Theory, New York: Open University Press.

12. Glanz, K, Rimer, BK, Viswanath, K. Health Behaviour and Health Education, San Fransisco: Jossey-Bass. 2008.

13. Foster LR, Byers ES, Sears HA. Middle school students' perceptions of the quality of the sexual health education received from their parents. The Canadian Journal of Human Sexuality. 2011 Jul 1;20(3):55.

14. Ghony, MD, Almansur, F. Metode Penelitian Kualitatif, Yogyakarta: Ar-Ruzz Media. 2012.

15. Rice, PL, Ezzy, D. Qualitative Research Methods, Australia: University Press. 2002.

16. Creswell, JW. Research Design. Yogyakarta: Pustaka Pelajar. 2012.

17. Walsh K, Brandon L. Their children's first educators: Parents' views about child sexual abuse prevention education. Journal of Child and Family Studies. 2012 Oct 1;21(5):734-46.

18. Frías SM, Erviti J. Gendered experiences of sexual abuse of teenagers and children in Mexico. Child abuse \& neglect. 2014 Apr 1;38(4):776-87.

19. Kenny MC, Wurtele SK. Children's abilities to recognize a "good" person as a potential perpetrator of childhood sexual abuse. Child Abuse \& Neglect. 2010 Jul 1;34(7):490-5.

20. UNICEF. Early Childhood Development New York:UNICEF. 2001.

21. Asampong E, Osafo J, Bingenheimer JB, Ahiadeke C. Adolescents and parents' perceptions of best time for sex and sexual communications from two communities in the Eastern and Volta Regions of Ghana: implications for HIV and AIDS education. BMC international health and human rights. 2013 Dec;13(1):40.

22. Wilson EK, Dalberth BT, Koo HP, Gard JC. Parents' perspectives on talking to preteenage children about sex. Perspectives on Sexual and Reproductive health. 2010 Mar 1;42(1):56-63.

23. Grossman JM, Charmaraman L, Erkut S. Do as I say, not as I did: how parents talk with early adolescents about sex. Journal of Family Issues. 2016 Jan;37(2):177-97.

24. Rosdiana D. Pokok-pokok pikiran pendidikan seks untuk remaja. Kesehatan Reproduksi Remaja. Program Seri Lokakarya Kesehatan Perempuan, Yayasan Lembaga Konsumen Indonesia, Ford Foundation, Jakarta. 1998:9-20.

25. Izugbara CO. Home-based sexuality education: Nigerian parents discussing sex with their children. Youth \& Society. 2008 Jun;39(4):575-600.

26. Hurlock, EB. Psikologi Perkembangan, Jakarta: Penerbit Erlangga. 1980.

27. Kesterton D, Coleman L. Speakeasy: a UK-wide initiative raising parents' confidence and ability to talk about sex and relationships with their children. Sex Education. 2010 Nov 1;10(4):437-48.

28. Hutchinson MK, Cederbaum JA. Talking to daddy's little girl about sex: Daughters' reports of sexual communication and support from fathers. Journal of Family Issues. 2011 Apr;32(4):550-72.

29. Habsyah, A, Martini, T, Lien, DA. Peran Ayah Vis-A-Vis Ibu dan Pranata Sosial Lainnya dalam Pendidikan Seks Remaja, Jakarta: The Atmajaya Research Centre. 1996. 